\title{
A IMPORTÂNCIA DO CONHECIMENTO HISTÓRICO NA FORMAÇÃO DE PROFESSORES DE EDUCAÇÃO FÍSICA E A DESCONSTRUÇÃO DA HISTÓRIA NO SINGULAR
}

Silvana VilodreGoellner *

\section{RESUMO}

O texto tem como objetivo desenvolver argumentos em favor da presença do conhecimento histórico nos cursos de formação de professores em Educação Física. Para tanto faz uma breve abordagem sobre a Historiografia da Educação Física brasileira para, posteriormente, esboçar algumas reflexões conceituais e metodológicas próprias ao ensino e à pesquisa em História destacando a impossibilidade de abordá-la no singular.

Palavras-chave: História. Educação Física. Educação.

Porque estudar História ${ }^{1}$ no curso de formação em Educação Física? Que aplicabilidade o conhecimento histórico tem na atuação cotidiana dos seus professores e professoras? Com tantas informações disponibilizadas pelas novas tecnologias de informação, porque é necessário ler autores clássicos da área? Se a Educação Física é uma área voltada para a saúde, a performance e a educação corporal de crianças, jovens e adultos, o que interessa 0 conhecimento histórico?

Perguntas como estas são frequentes na narrativa dos estudantes que, num primeiro momento, não entendem que uma disciplina como História da Educação Física possa trazer alguma contribuição à sua formação, a não ser o cumprimento de créditosobrigatórios que integram o currículo que determina sua formação.

Por entender que o conhecimento histórico é imprescindível na formação de professores de Educação Física desenvolvo alguns argumentos que possam não apenas justificar sua presença nos currículos mas, sobretudo, evidenciar que a História contribui para conhecer o presente e a nós mesmos.

\footnotetext{
${ }^{1}$ Devo esclarecer que uso a palavra História (em maiúsculo) para me referir àquilo que foi escrito e registrado sobre a história (em minúsculo), ou seja, o passado. Tal distinção se faz necessária porque usamos a mesma palavra para as duas situações. Para tentar demarcar essas diferenças utilizo, ainda a palavra Historiografia como sinônimo de História e conhecimento histórico para me referir ao estudo sobre algo que já se passou no decorrer da história. Ou ainda, que aconteceu no passado.
} 
No entanto, antes de desenvolver estes tópicos específicos julgo ser necessário esclarecer que partilho da concepção de que a Educação Física é uma prática de intervenção social que prescinde de conhecimentos advindos das ciências humanas e naturais para atuar com os diferentes elementos que compõe a cultura corporal (o esporte, a dança, o jogo, a ginástica, as lutas, entre outros) noâmbito da educação, da saúde e do lazer. A Educação Física, portanto, tem como função o trato pedagógico do movimento humano (BRACHT, 2000) e esse não é natural nem universal mas possui sentidos e significados consoante o contexto histórico no qual é produzido e vivenciado.

Como, então, formar profissionais sem sensibilizá-los para a percepção de quetudo tem história, inclusive o corpo e sua movimentação? Como qualificá-los a atuar no campo da saúde, do esporte, da educação e do lazer sem que tenham condições de entender que os discursos e as práticas que circulam no entorno desses campos não foram sempre os mesmos e que são constantemente modificados e ressignificados?

Entendo que o professor de Educação Física, independente de seu campo de trabalho (escola, academia, clube, parque e praças, hospitais, hotéis, laboratório de pesquisa, e inúmeros outros) carece de uma formação pedagógica sólida e, no meu entender, essa formação prescinde do conhecimento histórico. Razão pela qual se torna necessária a presença de uma disciplina como História da Educação Física e/ou Esporte na matriz curricular dos cursos de formação. Visão essa, diga-se de passagem, já presente nos primeiros cursos de formação implementados no Brasil.

\section{A Historiografia da Educação Física brasileira: uma breve referência}

No Brasil o conhecimento histórico compõe a grade curricular dos cursos de graduação em Educação Física desde os anos trinta do século XX, quando surgiram as primeiras iniciativas destinadas à formação de profissionais para atuarem nesse campo de trabalho, dominado até então, por médicos e militares. Desde esse período, diferentes matrizes epistemológicas e teóricas tem orientado não apenas as pesquisas históricas realizadas por autores brasileiros como também o trato com 0 conhecimento no interior das instituições escolares e universitárias.

De uma maneira bastante geral, é possível afirmar que de seus primórdios até aproximadamente os anos de 1980 as disciplinas relacionadas à História seja da Educação Física, seja do Esporte, estavam muito mais direcionadas para o estudo da 
memória esportiva nacional e internacional do que propriamente fundamentada em pesquisas historiográficas. Mais do que analisar os contextos onde emergiram as diferentes atividades corporais e esportivas vivenciadas por brasileiros e brasileiras, a centralidade desses estudos situava-se em descrever e memorizar datas, eventos, heróis e acontecimentos considerados significativos a estas práticas.

Com relação à Historiografia da Educação Física brasileira é possível destacar, como fez Victor Andrade de Melo $(1999)^{2}$, três fases iniciais no que respeita à produção do conhecimento histórico.

A primeira delas, de caráter embrionário, se desenvolveu através da adoção de livros de autores estrangeiros cujas obras mencionavam as origens e a evolução da Educação Física e do Esporte desde a Antigüidade Clássica. Nesse período, ou seja, desde o início do século XX até meados deste, existiam poucas iniciativas no Brasil de escrever sobre sua história, em especial, sobre os esportes ou mesmo sobre a Educação Física. Vale lembrar que é a partir dos anos 1930 queo Estado instituído se empenha em concretizar várias ações no campo específico das práticas corporais e esportivas, identificando a Educação Física e o esporte como espaços de intervenção na educação dos cidadãos, no sentido da valorização do corpo esteticamente belo e do aperfeiçoamento físico de corpos saudáveis e aptos, capazes de enfrentar os desafios da vida modernizada. ${ }^{3}$

Nessa primeira fase,a concepção que orientava os estudos históricos direcionava-se, grosso modo, para:

\begin{abstract}
a utilização bem restrita de fontes; um caráter "militante", a história servindo para provar e legitimar algo já previamente estabelecido irreversivelmente; a preocupação central exacerbada com 0 levantamento de datas, nomes e fatos; uma história pautada única e exclusivamente na aparência de grandes expoentes; uma historia que não busca uma periodização interna, preferindo se vincular a periodização política geral. Uma história traçada superficialmente em longos períodos (MELO, 1999, p. 15).
\end{abstract}

Mesmo percebendo diversas lacunas nessa produção é necessário reconhecer o esforço de diferentesautores que, na intenção de escrever e ensinar a história da

\footnotetext{
${ }^{2}$ Ainda que essa publicação seja datada de 1999, continua válida a análise feita pelo autor para os momentos iniciais da produção historiográfica da Educação Física brasileira.

${ }^{3}$ Corresponde a esse período, por exemplo,a criação do Ministério dos Negócios da Educação e Saúde Pública (1931); da Escola de Educação Física do Exército (1933); da Divisão de Educação Física do Departamento Nacional de Educação (1937); da Escola Nacional de Educação Física e Desportos, junto à Universidade do Brasil (1939); a instalação da Comissão Nacional dos Desportos (1939); e do Conselho Nacional dos Desportos, em 1941.
} 
Educação Física e do Esporte, produziram conhecimentos, mesmo que a partir de uma perspectiva ainda muito marcada pelo enaltecimento de heróis, eventos, instituições reforçando, assim o registro do passado a partir de uma narrativa descritiva e factual. Vele registrar, e é necessário ter essa compreensão, que muitos dos autores que nesse período escrevem sobre a Educação Física e oEsporte considerando seus aspectos históricos não tem formação no campo específico. Em sua maioria sãomilitares, cronistas esportivos, torcedores de um clube ou aficionados por essa prática cultural.

Uma segunda fase na produção do conhecimento histórico na Educação Física brasileira pode ser identificada a partir da obra de Inezil Penna Marinho (1915-1987), indiscutivelmente, uma dos maiores estudiosos da História da Educação Física e do Esporte desse país. Mesmo que seus escritosnão tenham rompido com a perspectiva da História factual-descritiva, celebrada também no período anterior, é considerada como um marco na Educação Física brasileira, tanto porque era muita bem referenciada teoricamente quanto porque resultava de um árduo trabalho de busca e utilização de fontes primárias. A importância da obra de Inezil Penna Marinho também foi destacada por Janice Mazo ${ }^{4}$ ao afirmar que"professores de todo Brasil foram formados, durante muitos anos, tendo na obra de Inezil o único eixo de ligação ao seu passado profissional" (GOELLNER ET ALL, p. 389).

Inezil Penna Marinho escreveu váriasobras sobre História da Educação Física e do Esporte brasileiros ${ }^{5}$, um fato inédito, visto que no período anterior os autores reportavam-se basicamente a reproduzir estudos produzidos por autores estrangeiros cujas temáticas desenvolvidas referiam-se, sobretudo, a história do Esporte e da Educação Física em outros contextos como, por exemplo, na Grécia Antiga, e na Idade Média ou, então, na França, na Alemanha, nos Estados Unidos, entre outros.

\footnotetext{
${ }^{4}$ O texto Pesquisa Qualitativa na Educação Física brasileira: marco teórico e modos de usar, foi escrito pelos professores da disciplina Instrumentos para Coleta e Investigação em Pesquisa Qualitativano Programa de Pós-Graduação em Ciências do Movimento Humano da Universidade Federal do Rio Grande do Sul contemplando cinco eixos: etnografia, pesquisa historiográfica, análise de discurso, análise de imagens e ética em pesquisa. $O$ eixo $A$ pesquisa historiográfica ea produção do conhecimento científico no campo da Educação Física brasileira (1987-2008) é de autoria de Janice ZarpellonMazo, a quem credito a pertinência da discussão e análise.

${ }^{5}$ Maiores informações podem ser acessadas na catalogação das publicações delnezil Penna Marinho desenvolvida pelo Centro de Memória do Esporte (UFRGS). Disponível em http://www.esef.ufrgs.br/ceme/projetos/inezil/catalogaao.html ou na homepage do Centro de Memória Inezil Penna Marinho, da UFRJ. Disponível em http://www.ceme.eefd.ufrj.br/apresenta/home2.html
} 
Inezil marcou a diferença pois escreveu sobre a Educação Física e o Esporte no Brasil $^{6}$ incluindo ainda a capoeira. ${ }^{7}$

Para além de Inezil, outros autores também se farão presentes nessa segunda fase, que se diferencia da anterior exatamente pelo desenvolvimento de pesquisas relacionadas ao contexto nacional. A concepção historiográfica que sustenta essas pesquisas é marcada, como na fase anterior, pela descrição e memorização de fatos, datase nomes sem haver uma análise do material pesquisado compondo, o que Peter Burke (1991) denominou como história episódica. Na análise desenvolvida por JaniceMazo,

\begin{abstract}
Esta forma de fazer História, então dominante no campo da Educação Física e dos esportes no Brasil, encontraria fortes reações por parte das novas abordagens historiográficas que a sucederam, sobretudo aquelas encampadas por autores da década de 1980. Numa visão que se pretende evolucionista, a velha história da Educação Física foi duramente acusada de privilegiar a mera descrição dos acontecimentos e datas, na longa duração, ignorando uma análise mais aguçada de seus aspectos particulares de tempo e espaço. Soma-se a isto, a indefinição e indiferenciação de um conceito claro para a Educação Física como objeto de estudo e, sobretudo, de apoiar suas reflexões em padrões corporais e culturais de movimento que remetiam as práticas atuais às cristalizações de representações gregas e romanas (GOELLNER ET AL, 2010, p, 390).
\end{abstract}

A partir dos anos 1980 outras concepções historiográficas adquirem visibilidade na pesquisa brasileira e esta influenciará significativamente o trabalho com a disciplina de História da Educação Física e do Esporte nos cursos de graduação, marcando o início daterceira fase apontada por Melo (1999).

Esse período é bastante fecundo para o Brasil. Período no qual a Ditadura Militar chegava a seus últimos suspiros e aquilo que se convencionou chamar de "Abertura Política" mostrava-se diante de nossos olhos. Em agosto de 1979 o General Figueiredo, sancionou a Lei da Anistia e no seu rastro, despontaram várias outras conquistas $^{8}:$ o retorno dos exilados políticos, o fortalecimento dos movimentos sociais,

\footnotetext{
${ }^{6}$ Destaque para as obras Contribuição para a História da Educação Física no Brasil (1943);História da Educação Física e Desportos no Brasil, Volumes I e II (1952); Volume III (1953); Volume IV (1954); História Geral da Educação Física (1956); Rui Barbosa: paladino da Educação Física no Brasil (1975)

${ }^{7}$ Subsídios para a História da Capoeiragem no Brasil (1956);

${ }^{8}$ Registro como conquista e não concessão pois a "Abertura Política" resultou da luta entre diferentes setores da sociedade brasileira. Não podemos esquecer que, em seu nome, muitos brasileiros e brasileiros foram desaparecidos, torturados e mortos.
} 
as greves, a legalização do Partido Comunista e a construção do Partido dos Trabalhadores, o Movimento Diretas Já, o Movimento de Mulheres, enfim, idéias e ações que integravam nosso cotidiano.

No campo da Historiografia brasileira é possível identificar que a História episódica perde sua hegemonia e as análises críticas, politizadas e contextualizadas invadem a produção acadêmica brasileira. Fundamentadas no marxismo despontam várias produções cujo fazer historiográfico privilegia não apenas a descrição dos fatos mas, sobretudo, análises que objetivam entender a constituição da Educação Física e dos Esportes a partir de um viés crítico. Nessa perspectiva, para além de destacar datas, acontecimentos, eventos e personagens, torna-se imperante analisá-los e interpretá-los à luzdo contexto social, político, econômico e cultural no qual foram produzidos.

Tanto quanto a vertente marxista, outras abordagens teóricas e metodológicas começaram a frutificar na área cujas pesquisas foram e ainda sãofrequentemente citadas, nas ementas que constituem a disciplina de História da Educação Física e/ou Esporte em vários cursos de formação.

Aportes teóricos advindos da Escola dos Analles, Micro-História, História Oral, História Cultural, Nova História, História Social, História do Cotidiano, História PósEstruturalista, História das Mulheres, tornam-se visíveis nos estudos e pesquisas desenvolvidos na Educação Física brasileira indicando um movimento de "renovação historiográfica"9 quando comparadas às etapas anteriores nas quais a História factual e descritiva mantinha certa dominância no campo. Renovação essa que pode ser creditada, segundo Janice Mazo, a expansão dos cursos de Pós-Graduação em Educação Física nas universidades brasileiras a partir da década de 1990 possibilitando a ampliação de estudos historiográficos. "Percebe-se, a partir deste movimento, uma atitude mais cuidadosa dos pesquisadores com relação ao campo da produção historiográfica no que tange aos pressupostos teóricos eleitos, à produção discursiva e à construção de novas narrativas através das fontes (GOELLNER ET AL, 2010, p. 390).

Feita essa breve referência à inserção do conhecimento e da pesquisa historiográfica na Educação Física brasileira, considero importante registrar que esse caminhar não se deu de modo contínuo e linear. Se olharmos as ementas das disciplinas e as investigações em desenvolvimento nos dias atuais é possível identificar todas as abordagens aqui mencionadas, inclusive, a da História Episódica

\footnotetext{
${ }^{9}$ Sobre esse tema recomendo a leitura do texto Renovação Historiográfica na Educação Física brasileira, de Marco Aurélio Taborda de Oliveira (2007)
} 
com ênfase nos seus aspectos descritivos e factuais. Isso se dá porque, como já mencionei anteriormente, a História não é sinônimo de história. Ou seja, aquilo que se registra do passado não necessariamente é aquilo que aconteceu no passado ou ainda não é o próprio passado.

Porque então, estudar História na formação de professores de Educação Física?

\section{A História, a Educação Física e suas múltiplas possibilidades}

A compreensão da História, como a ciência que estuda o passado há muito vem construindo representações acerca do fazer historiográfico assinalando ser a necessidade de fazer lembrar uma preocupação humana.

Fazer lembrar, mas tambémfazer esquecer, na medida em que, ao contar sobre um tempo que já não é mais, a História tanto pode "celebrar" o que deve ser lembrado quanto "invisibilizar" o que deve ser esquecido. Afinal, como tenho mencionado desde o início do texto, aHistória não é sinônimo de passado mas uma narrativa sobre o passado (PESAVENTO, 2003; JENKINS, 2004). Nesse sentido é necessário pensar que a narrativa históricaé resultante de um entrelaçamento de objetividades e subjetividades, de percepções, de olhares, de possibilidades de análises e estas são sempre datadas. Em última instância, a História é, ela própria, historicamente datada, está ancorada no tempo e tem narrado o mundo de acordo com interesses, pessoais, políticos, sociais, econômicos, culturais, étnicos, etc, evidenciando, sobretudo, a impossibilidade de descrever o real como ele é. Nas palavras de Michel de Certeau "Toda a pesquisa historiográfica se articula com um lugar de produção sócio-econômico, político e cultural e está submetido a imposições, ligada a privilégios, enraizada em uma particularidade" (1982, p. 66). Em outras palavras: a História não é neutra e traduz-se em um dos muitos discursos que existem acerca do mundo, do real e da humanidade tendo sua territorialidade atrelada ao que já aconteceu, ao passado.

Ainda que sejam palavras próximas, vale ressaltar, que História e passado (história) são coisas absolutamente diferentes visto que

o passado e a História não estão unidos um ao outro de tal maneira
que se possa ter apenas uma leitura histórica do passado. O passado
e a História existem livres um do outro; estão muito distantes entre si
no tempo e no espaço. Isto porque o mesmo objeto de investigação
pode ser interpretado por diferentes práticasdiscursivas (...) ao
mesmo tempo em que, em cada uma destas práticas, há diferentes
leituras interpretativas no tempo e no espaço (JENKINS, 2004, p. 24). 
A partir dessa explicitação podemos indagar: O que é, afinal, estudar e pesquisar aEducação Física e do Esporte considerando seus aspectos históricos?

Seria, por exemplo, encontrar a verdade do passado, narrar seus acontecimentos mais importantes, enaltecer os nomes de homens e mulheres que figuram como personalidadesheróicas? Não seria, quem sabe, trazer para o tempo presente alguns ideais da 'Civilização Clássica cujas representações estéticas ainda hoje se vinculam ao universo iconográfico da Educação Física e Esportes? Pensemos:não é, ainda, o Discóbulo, famosa escultura do artista grego Miron a imagem que seguidamente aparece ilustrando convites de formatura de diferentes Escolas de Educação Física, muitas das quais a disciplina História da Educação Física e/ou Esporte se não é designada como menor, nem existe? E os Jogos Olímpicos não são, ainda hoje, estudados como referências de ações voltadas à celebração da paz mundial e a confraternização de diferentes nações, etnias e culturas mesmo num tempo onde a corrupção, os interesses econômicos, o dopping,o terrorismo, a exacerbação da performance são elementos que também constituem esses Jogos?

Cabe aqui uma pergunta: É possível falar em História da Educação Física e/ou Esporte no singular?

Se a História é uma narrativa que tanto pode dizer do passado como também ocultá-lo não há possibilidade alguma de pensar que exista uma História da Educação Física e/ouEsporte senão em Histórias. Lembremos que aquilo que nos chega do passado não é o passado em si mas o registro que alguém fez dele. Nas palavras de Jenkins "o passado que "conhecemos" é sempre condicionado por nossas próprias visões, nosso próprio "presente". Assim como somos produtos do passado, assim também o passado conhecido (a história) é um artefato nosso. Ninguém, não importando quão imerso esteja no passado, consegue despojar-se de seu conhecimento e de suas pressuposições" (2004, p. 33).

Pensando especificamente no campo da História da Educação Física e/ou Esporte é possível vislumbrar um horizonte pleno de multiplicidades, de interpretações, de olhares, de formas de narrar vários acontecimentos como, por exemplo, história de diferentesmodalidades esportivas, de instituições 
(clubes, associações esportivas, comitês olímpicos, federações e confederações), pessoas (atletas, técnicos, dirigentes, professores, etc), eventos, competições de nível internacional, nacional, regional e local. A história de um clube, por exemplo, pode ser narrada apenas ressaltando seus dirigentes, suas conquistas e glórias, seus méritos. Como também, dependendo de quem registra essa história, pode evidenciar as disputas de poder, os fracassos e insucessos, ou seja, àquilo que está nas zonas de sombra da trajetória dessa instituição. Jenkins, outra vez, nos ajuda a pensar sobre esse aspecto quando afirma que

\begin{abstract}
Não é possível relatar mais que uma fração do que já ocorreu, e o relato de um historiador nunca corresponde exatamente ao passado: o simples volume desse último inviabiliza a História total. A maior parte das informações sobre o passado nunca foi registrada, e a maior parte do que permaneceu é fugaz. (...) A História depende dos olhos e da voz de outrem; vemos por intermédio de um intérprete que se interpõe entre os acontecimentos passados e a leitura que dele fazemos (2004, p.30-32).
\end{abstract}

A participação das mulheres no esporte ilustra muito bem essa afirmação. Basta ler muitos documentos que se propõem a contar a história de várias modalidades esportivas e o que encontramos é a narrativahistórica dos homens! Pouca ou nenhuma menção se faz as mulheres, como se elas não tivessem participação alguma na estruturação do esporte brasileiro. Com isso quero afirmar que a falta de registro sobre as mulheres no esporte não significa a sua ausência, mas a ausência de registros sobre essa participação.

Um bom exemplo para refletir sobre essa questão é o Museu do Futebol, localizado no Estádio do Pacaembú, em São Paulo cuja missão é "investigar, divulgar e preservar o futebol como manifestação da cultura brasileira" ${ }^{10}$. O que se vê ao percorrer seus acervos e exposições é que esse museu tematiza o futebol praticado por homens ${ }^{11}$. A participação das mulheres é silenciada como se elas não estivessem, há muito tempo, atuando na modalidade, seja como

\footnotetext{
${ }^{10}$ Disponível em http://www.museudofutebol.org.br/o-museu/

${ }^{11}$ Sobre esse tema ler: O Museu do Futebol e uma história parcial: Ou não há futebol feminino no Brasil?, deEnny Vieira Moares
} 
jogadoras, treinadoras, espectadoras, torcedoras, gestoras, árbitras, enfim, como se não fizessem parte dessa História.

Dado esse exemplo, quero enfatizar que é impossível tomar aHistória da Educação Física e/ou Esportes no singular pois são muitos os seus temas, objetos, problemas, instrumentos analíticos e fontes. A tarefa de registrar a história, grosso modo atribuída aos historiadores, possibilita múltiplas interpretações de um mesmo acontecimento cujo resultado (ou seja a narrativa) vai depender "das fontes existentes, dos recursos teórico-metodológicos escolhidos e de um olhar, dentre vários outros possíveis, marcado por nossa atualidade, vale dizer, por nossa inserção cultural e social, enfim, por nossa própria subjetividade" (RAGO, 2004, p. 10).

Nas palavras de Sandra Pesavento "tudo o que foi um dia poderá vir a ser contado de outra forma, cabendo ao historiador elaborar uma versão plausível, verossímil de como foi. Mesmo admitindo uma certa invariabilidade no ter sido, as formas de narrar o como foi são múltiplas e isso implica colocar em xeque a veracidade dos fatos" (2003, p. 51). Nesse sentido é possível afirmar que o trabalho historiográfico busca se aproximar o máximo possível do que aconteceu um dia e que o historiador pode relatar um tempo transcorrido mesmo que esse mesmo tempo ou fato relatado possa ser objeto de outras tantas versões. A História, portanto, não trabalha com "a verdade" mas com a verossimilhança.

A impossibilidade de uma História no singular é uma boa justificativa para o incentivo ao estudo e à pesquisa nos cursos de formação emEducação Física na medida em que poderá fomentar a emergência de outras versões sobre algum tema já investigado ou ainda de novos temas como, por exemplo, investigações sobre contextos locais e regionais, sobre diferentes etnias, sobre pequenos clubes e associações esportivas, entre outras possibilidades.

Outra justificativa para a sua presença é que ao estudarmos a Educação Física e/ou Esportes considerando sua historicidade compreendemos que aquilo que hoje conhecemos, vivenciamos e valorizamos nem sempre foi assim. A exigência, por exemplo,de um corpo magro e moldado pela exercitação física é recente e decorre do movimento fitness surgido no contexto americano nos anos 70 do século XX. Isto é, nem sempre as imposiçõesforam essas e nem sempre esse foi considerado um corpo belo e 
saudável como o é na atualidade. Ao agir assim estamos desnaturalizando o que parece ser natural e, assim, a História mostra-se necessária porque contribuipara entender e enfrentar os problemas humanos (BLOCH, 2001), inclusive, os específicos da nossa área de conhecimento.

Estudar e pesquisar as Histórias da Educação Física e/ou Esporte é, portanto,estabelecer nexos entre diferentes épocas estando ciente de que 0 passado é algo que não se pode modificar, apenas compreender. O presente, no entanto, é algo em construção cuja história depende também de nossa ação.

\section{O estudo e a pesquisa nos cursos de formação: Histórias em construção}

Identificar a História como uma possibilidade de conhecer mais sobre aEducação Física e Esportes traduz uma postura de investigação que permite conhecer mais profundamente as ideologias, os valores, os preconceitos, as premissas sobre as quais se fundaram essas práticas. No entanto uma ressalva deve ser feita: estudar ou pesquisar História da Educação Física e/ou do Esporte não é apenas aguçar a curiosidade, agrupar dados, datas, feitos históricos, nomes de heróis e heroínas. Pressupõe método investigativo, adensamento teórico, rigor metodológico, disciplina e dedicação.

Vale lembrar que para abordar historicamente um tema (seja no estudo, seja na pesquisa) alguns cuidados são fundamentais. Um deles reside na questão das fontes escolhidas, entendidas aqui, como aqueles documentos, depoimentos, imagens sobre as quais vamos debruçar nosso olhar. Nesse particular é pertinente ressaltar que aquilo que determina as fontes a serem pesquisadas é, exatamente o tema a ser investigado, isto é, aquilo que está sendo problematizado. Feita essa escolha (delimitação do tema),começa a aflorar a pesquisa visto que, em História "tudo começa com o gesto de separar, de reunir, de transformar em "documentos" certos objetos distribuídos de outra maneira. Esta nova distribuição cultural é o primeiro trabalho do historiador" (CERTEAU 1982, p. 65).

Quanto mais variadas forem as fontes mais fecunda pode ser a pesquisa. Documentos oficiais, jornais, revistas, diários, correspondências, atas, livros de registros, súmulas e tantos outros documentos escritos podem se tornar fontes importantes de pesquisa bem como fotografias, objetos, 
equipamentos esportivos, medalhas, prédios arquitetônicos, monumentos, vestuário, quadros, filmes.... Enfim, tudo pode vir a ser uma fonte histórica desde que articulada ao problema a ser investigado e ao período da investigação. Ou seja, qualquer produção, seja ela de uma pessoa, grupo, instituição pode vir a contribuir para o entendimento de uma determinada época e isso só será possível se houver uma articulação com a pergunta inicial a que se quer responder.

Em outras palavras: um documento, uma fotografia, umabola, a arquitetura de um estádio, os equipamentos de lazer de uma praça, uma medalha não são fontes históricas em si. O pesquisador é que lhe atribui esse significado a partir das questões que levanta para pesquisar, das indagações que faz sobre esses objetos: quando surgiram, com quais objetivos, quem os produziu? Quem os conquistou? Em que circunstâncias? Ou seja, eles se transformam em fonte histórica porque foram indagados por alguém e esse alguém Ihes conferiu voz. Assim, o que indica o fato de uma chuteira ou um uniforme esportivo ser uma fonte histórica é, exatamente o problema a ser investigado ou, fora da pesquisa, as perguntas que um torcedor pode fazer sobre o surgimento de seu clube, por exemplo.

Nesse sentido tanto as fontes documentais quanto as fontes iconográficas ou sonoras são de igual e tamanha importância. Essa observação se dá porque até meados dos anos trinta do século $X X$ o que denominamos de História Episódicaestabelecia certas hierarquias entre as fontes sendo as documentais ou escritas aquelas que ganhavam maior ou talvez única relevância visto serem consideradas como mais "verdadeiras". Digamos que esta percepção tenha começado a ser posta em xeque pelos historiadores franceses da Escola dos Analles que,ao questionarem a noção de testemunho, advertiam ser necessária a ampliação da noção de fonte. Marc Bloch, no seu livro Introdução à História, ao refletir sobre a diversidade das fontes afirma se constituir uma grande ilusão imaginar que a cada problema histórico corresponda um tipo único de documento, especializado nessa função. "Pelo contrário, quanto mais a investigação procura alcançar os factos profundos, menos lhe é permitido esperar outra luz que não seja a dos raios convergentes de testemunhos diversíssimos na sua natureza" (s.d, p. 62). 
Imaginemos uma situação: investigar a analisar a inserção das mulheres brasileiras em uma modalidade esportiva como, por exemplo, a natação. Para uma análise como esta, muitas podem ser as fontes acessadas, tanto na quantidade como na diversificação. Além de registros oficiais de clubes, jornais e revistas é muito pertinente recorrer a outros vestígios do passado como, por exemplo, fotografias (seja aquelas publicadas nos jornais ou guardadas em álbuns de família), depoimentos de nadadoras antigas ou de pessoas que as acompanharam, filmes, trajes de banho, programas de competições, medalhas, diários pessoais, troféus, entre outros, pois esses "documentos"são testemunhos do tempo passado e nos auxiliam a entender quando as mulheres iniciaram a nadar publicamente, as provas que disputavam, as resistências e os incentivos que tinham por parte de familiares, dirigentes esportivos, educadores, etc. Com isso quero dizer que uma imagem, uma poesia, uma música, um traje esportivo, uma bola, a arquitetura de uma praça de lazer podem ser observadas como importantes fontes históricas que dizem coisas de um tempo que já passou. Razão pela qual devemos olhar para esses objetos e locais reconhecendo neles a possibilidade de nos fornecerem infinitas interpretações aprofundando, assim, as nossas análises.

Para além da escolha e interpretação das fontes, a pesquisa histórica exige cuidado, atenção, dedicação e minúcia. Exige, sobretudo reflexão pois pesquisar é pensar. E pensar é muito diferente do que ter opinião sobre algo. Pensar pressupõe racionalidade, reflexão, exercício argumentativo, práticas essas essenciais no mundo contemporâneo onde as novas tecnologias computacionais e informacionais associadas à forte presença dos meios de comunicação de massa promovem o consumo fácil, e por vezes, superficial da informação.

Como já mencionei, quanto mais diversas forem as fontes de pesquisa mais possibilidade se tem de aproximar-se do que aconteceu no passado. No entanto, não basta acessar uma infinidade de fontes se quem as está investigando não souber lhes dar voz, ou seja, se não tiver a capacidade de confrontá-las e de colocá-las em diálogo para assim reunir condições e argumentos e, então, narrar o que está sendo analisado.

Nesse particular, gostaria de me dedicar um pouco a pensar sobre a imagem como fonte da pesquisa historiográfica pois entendo que os 
significados das imagens são também os significados de como elas se mostram. Tal recorte justifica-se porque vivemos em uma cultura ocularcêntrica (MIRZOEFF, 2003) e também por perceber que seu uso tem sido recorrente na produção acadêmica das Humanidades, inclusive, nas pesquisas historiográficas desenvolvidas pela Educação Física brasileira.

Em que pese a recorrência a registros iconográficos de diferentes natureza (gravuras, fotografias, pinturas, desenhos, etc.) essa apropriação não se deu diferentemente de outras áreas do conhecimento, inclusive no campo das ciências sociais e humanas. Na História, por exemplo, Uspiano Meneses (2003) indica que o uso da imagem como ilustração tornou-se lugar comum não apenas no passado, mas inclusive, em investigações contemporâneas.

Ainda que o caráter ilustrativo da imagem seja uma forma bastante presente de sua aplicação na pesquisa historiográficacontemporânea, penso a imagem como um "texto a ser lido, imaginado, observado, reconstruído no seu significado" (GOELLNER; MELLO, 2001, p. 122), pois, cada vez que debruçamos nosso olhar sobre uma mesma imagem, podemos entendê-la de diferentes modos. A imagem, portanto, não é neutra nem inocente. A imagem, que é texto, contém significados e estes devem ser analisados considerando $o$ contexto cultural no qual são produzidas e consumidas. Razão pela qual, ao analisarmos uma imagem, não estamos dizendo a verdade sobre ela mas a interpretando e essa interpretação vai depender do nosso modo de ver. Como registra John Berger (1999, p. 23) "nunca examinamos apenas uma única coisa; sempre estamos examinando a relação entre as coisas e nós mesmos" entre o que nossa biografia pessoal e o contexto social no qual vivemos nos permite ver.

Vale lembrar que quando me refiro a imagem estouincorporando, também, as imagens em movimento (com ou sem som) facilmente veiculadas pelo cinema, televisão e, recentemente, pela rede mundial de computadores. Essas imagens têm se constituído como campo fecundo de análises qualitativas nas diferentes áreas das Humanidades. Por essa razão, interessa registrar que as narrativas contemporâneas, sobretudo as tecnológicas que lidam com a captação e registro de imagens e sons (TV, cinema, internet) incorporam no seu processo de produção elementos que acabam por promover uma espécie de educação cultural da inteligência visual. 
Para encerrar essa digressão sobre a imagem gostaria de registrar que considero a imagem como uma fonte importante para o estudo e a pesquisa em Educação Física e Esportes pois, como afirma Alberto Manguel:

\begin{abstract}
As imagens que formam nosso mundo, são símbolos, mensagens e alegorias. Ou talvez sejam presenças vazias que completamos com o nosso desejo, experiência, questionamento e remorso. Qualquer que seja o caso, as imagens, assim como as palavras, são matérias do que somos feitos (2000, p. 21).
\end{abstract}

Diante desse contexto, cabe perguntar: Como sensibilizar os alunos dos cursos de graduação a estudar e pesquisar histórias?

Talvez o primeiro grande desafio seja evidenciar que a História não é matéria morta e queseu estudo é imprescindível para conhecer o presente, entender o mundo e a nós mesmos e, de posse dessa compreensão, projetarmos o futuro. Futuro esse que é feito pela ação concreta de mulheres e homens cujas histórias pessoais expressam vivênciasque, ao serem partilhadas, fazem brotar outras transformando o agir humano em um processo sempre inovador porque sempre diferente e imprevisível.

Talvez seja, também, fornecer elementos para que a curiosidade tenha espaço em sala de aula de modo a desafiar a inteligibilidade e sensibilidade dos alunos. Nessa direção, torna-se necessário desenvolver estratégias que promovam o despertar de uma atitude investigativa, criadora que faça pulsar o desejo de conhecer algo já conhecemos ou que pouco conhecemos. Uma atitude permeada, também, pela desconfiança. Ou seja, que desafie os alunos a desconfiar dos conhecimentos e não apenas consumi-los, porque desconfiar implica levantar outras possíveis respostas e também outros possíveis caminhos para se chegar a uma ou várias possíveis respostas. Implica apurar o olhar para uma leitura mais atenta, aguçar a inteligência e ir além da aparência do que se lê e vê. Ou seja, permite que outras Histórias da Educação Física e dos Esportes possam ser narradas e conhecidas de modo a conferir visibilidade àqueles que os discursos oficiais silenciaram.

Para finalizar cito um de nossos grandes poetas, Ferreira Gullar (1999, p. 23), quando escreve. 
E a história humana não se desenrola apenas nos campos de batalha e gabinetes presidenciais.

Ela se desenrola também nos quintais, entre plantas e galinhas, nas ruas do subúrbio, nas casas de jogos, nos prostíbulos nos colégios, nas usinas, nos namoros de esquina.

Disso eu quiz fazer a minha poesia.

Dessa matéria humilde e humilhada,

dessa vida obscura e injustiçada porque o canto não pode ser um traição à vida, e só é justo cantar se o nosso canto arrasta consigo as pessoas e as coisas que não tem voz.

\section{REFERÊNCIAS}

BERGER, John. Modos de ver. Rio de Janeiro: Rocco, 1999.

BLOCH, Marc. Introdução à História. Lisboa: Publicações Europa-América, s.d.

Apologia da história ou o ofício do historiador. Rio de Janeiro: Jorge Zahar, 2001.

BRACHT, Valter. Educação Física \& Ciência: cenas de um casamento (in)feliz. Revista Brasileira de Ciências do Esporte.v. 22. n. 1, p. 53-63, set., 2000.

BURKE, Peter. A história dos Analles (1929-1989):a Revolução francesa da historiografia. São Paulo: Unesp, 1991.

CERTEAU, Michel de. A escrita da História. Rio de Janeiro: Forense Universitária, 1982.

FERREIRA GULLAR. Toda Poesia. Rio de Janeiro: José Olympio, 1990.

JENKINS, Keith. A História repensada. São Paulo: Contexto, 2004.

LE GOFF, Jacques. A História do Quotidiano. In: ARIÈS, P., DUBY, G. e LE GOFF, Jacques. História e Nova História. Lisboa: Teorema, 1994.

GOELLNER, Silvana. V.; MELO, VictorA de. Educação física e história: a literatura e a imagem como fontes. In: CARVALHO, Y. M.; RUBIO, K. (Org.). 
Educação física e ciências humanas.São Paulo: HUCITEC, 2001. p. 105114.

GOELLNER, Silvana V. et al. Pesquisa qualitativa na Educação Física Brasileira: marco teórico e modos de usar. Revista da Educação Física, v. 21, p. 381-410, 2010.

MANGUEL, Alberto. O espectador comum: a imagem como narrativa. In: MANGUEL, A. (Org.). Lendo imagens. São Paulo: Companhia das Letras, 2000. p. 15-34.

MARINHO, Inezil P.História da educação física e desportos no Brasil. Volume I e II. Rio de Janeiro: DEF-MES, 1952.

. História da educação física e desportos no Brasil. Volume III. Rio de Janeiro: DEF-MES, 1953.

História da educação física e desportos no Brasil. Volume IV. Rio de Janeiro: DEF-MES, 1954.

MELO, VictorA. de História da Educação Física e do Esporte no Brasil: panorama, perspectivas e propostas. Rio de Janeiro: IBASA, 1999.

MENESES, Uspiano T. B. de. Fontes visuais, cultura visual, História visual: balanço provisório, propostas cautelares. Revista Brasileira de História. São Paulo, v. 23, n. 45, p. 11-36, 2003.

MIRZOEFF, Nicholas.Una introducción a la cultura visual.Barcelona: Paidós, 2003.

MOARES,Enny Vieira de. O Museu do Futebol e uma história parcial: ou não há futebol feminino no Brasil?. Recorde: revista de História do Esporte, V. 2, n. 1, junho/ 2009, p. $1-5 . \quad$ Disponível em 
http://www.sport.ifcs.ufri.br/recorde/pdf/recordeV2N1 2009 22.pdf. Acesso em 21/02/2012.

OLIVEIRA, Marco Aurélio Taborda de. Renovação historiográfica na educação física brasileira. SOARES,C. L. (org.) Pesquisas sobre o corpo: Ciências humanas e ducação.Campinas. Autores Associados, 2007, p. 35-38

PESAVENTO, Sandra J. História \& História Cultural. Belo Horizonte: Autêntica, 2003.

RAGO, Margareth. A História repensada com ousadia. In: JENKINS, K. A História repensada. São Paulo: Contexto, 2004, p. 9-13. 


\title{
POSTGRADUATE PROGRAMS IN PHYSICAL EDUCATION IN BRAZIL: THE PHENOMENON OF HYPER-PRODUCTIVITY AND CULTURAL FORMATIN
}

\begin{abstract}
Although the problem of looking after points to gain in order to upgrade the Lattes CV and be well ranked at the Capes of researchers and post-graduation programs in Brazil is reaching outrageous levels, just a few people, until now, have dared to make a more critical analysis of the this problem that exists among us, specially in what concerns the lack of responsibility of the curent researches related to the socio-cultural level of the local scientific researches. This article raises some of the problems on this aspect, questioning the post-graduation in physical education in the country and the uncontrolled rush of the people into publishing their papers internationally, which is the only thing that mantains programs and researchers actives on Capes.
\end{abstract}

Keywords: Post-Graduate Program. Scientific production.Cultural formation.

\begin{tabular}{lrrrrrrr}
\hline POSTGRADO & EN EDUCACIÓN & FÍSICA & EN & BRASIL: & EL & FENÓMENO & DE \\
HIPERPRODUCTIVIDAD Y FORMACIÓN CULTURAL & & & & &
\end{tabular}

\section{RESUMEN}

La cuestión de la carrera por puntos para estar bien clasificados en el currículo Lattes - CAPES per investigadores y los programas de postgrado en Brasil están alcanzando dimensiones absurdas. Pocos se atrevieron a hacer un análisis más crítico de esta cuestión entre nosotros, sobre todo en relación con la falta de responsabilidad y importancia sociocultural en la producción científica actual local. Este artículo plantea algunos problemas en este sentido, cuestionando el postgrado en educación física en el país y la desenfrenada carrera detrás de publicaciones internacionales para mantener programas y investigadores activos en CAPES y sólo eso.

Palabras clave: Postgrado. Producción científica. Formación cultural. 